\title{
Significance of Short Story Cycle in Rachel Joyce's A Snow Garden and Other Stories: An Analytical Study Using Complexity Theory
} https://doi.org/10.33806/ijaes2000.22.1.13

\author{
Shaju Nalkara Ouseph \\ Arab Open University, KSA
}

Received on 1.12.2020

Accepted on 22.9.2021

Published on 1.1.2022

\begin{abstract}
Rachel Joyce's short story collection A Snow Garden and Other Stories (2015) is composed of seven stories which occur during a fortnight of the holiday, Christmas season. The collection uses narrative techniques which make it a unique set of stories. The stories have an urban setting and examine the intricacies of human relationships. The sense of interconnection highlighted by Joyce in the stories elevates it to a short story cycle. A short story cycle consists of individual stories which can stand on their own as complete narratives while also maintaining fictional links running through all the stories. The paper is an attempt to establish A Snow Garden and Other Stories as a short story cycle. It also argues that by narrating the interconnected nature of human lives Joyce's work is exploring life as a complex system. As a scientific philosophy complexity theory explores the behavior of complex systems including human societies. Complex systems are self-organizing, dynamic, evolving networks that operate without any centralized control; similar to human societies. This paper will apply the principles of complex systems to reveal patterns of human behavior represented in Joyce's work.
\end{abstract}

Keywords: complex system, complexity theory, human relationships, short story cycle

\section{Introduction}

A Snow Garden and Other Stories (2015) by Rachel Joyce exploits the narrative potential of the short story to succinctly portray the bittersweet transitions happening in the lives of a handful of characters. Joyce's work consists of seven stories unraveling in the backdrop of the Christmas, holiday season. Even while focusing upon the celebratory, materialistic aspect of the holiday season, the stories limelight human relationships in flux. With the exception of the fourth story, "The Boxing Day Ball", which happens in 1962, the other stories are set in the present day and play out within the time frame of a fortnight. The urban setting of the stories is exploited by Joyce to comment upon loneliness, precarious family ties, empathy, mental health, and transience of life. Yet, even while considering the thematic unity of the stories, they exhibit connections on a deeper scale. There are recurring characters, and specific objects which project a semblance of interconnectedness in the narrative structure of $A$ Snow Garden. This interconnected nature transforms the story collection into a short story cycle. Abby Werlock's definition of a short story cycle suits Rachel Joyce's collection; he says that in a short story cycle, "When read sequentially, the stories - although each is a complete entity on its own - display a coherent pattern of character and theme that binds the stories together" 
(2010, p. 610). Joyce's collection of stories exhibits the tendencies which are associated with a short story cycle by narrating stories which are simultaneously standalone and interconnected.

The stories in A Snow Garden commence with the tale of a divorced, middleaged mother overcoming rejection and heartbreak - "A Faraway Smell of Lemon". The protagonist, forty-seven-year-old Binny, is forced to confront the messiness of her life before Christmas when her boyfriend, Oliver, breaks-up with her. The story narrates how Binny finds comfort in an unlikely space and from an unlikely source - from the assistant of a shop selling cleaning products. The next story "The Marriage Manual" concerns the repressed tensions in the seemingly idyllic married life of Alan and Alice. These burst forth on Christmas Eve while they assemble a present for their only son Will, a lonesome twelve-year-old. The third story titled "Christmas Day at the Airport" narrates the experience of a young pregnant woman Magda who experiences labor pains while stranded at an airport on Christmas day. The 'central' or fourth story "The Boxing Day Ball" takes place in 1962 and concerns Maureen, a girl in a red coat who traverses a snow bound landscape with her companions to attend a Christmas party. The girl in a red coat becomes a central image connecting all the other six stories. "A Snow Garden", the fifth story, is about Henry, a divorced father with mental health issues, having to engage his two sons who are visiting for the holiday season. The penultimate story "I'll be Home for Christmas" concerns Sylvia who is staging a late family Christmas gathering for her son who has become a singing celebrity. The collection concludes with "Trees" coming full circle to narrate the story of Oliver from the first story of the collection. It deals with his life post-separation from Binny and with his ageing father who has a strange desire to plant trees on New Year's Eve (Sethi, 2016).

Joyce appropriates the form of the short story cycle to describe interconnected patterns of human behavior. This paper will engage with two primary concerns; firstly, to indisputably establish A Snow Garden and Other Stories as a short story cycle by examining critical readings on the form of the short story cycle and verifying its compatibility; and secondly to use the principles of Complexity theory to read Joyce's work as an attempt to portray human society as a complex system. The principles of complexity theory can be utilized to study human interactions in today's globalized scenario. Complexity theory empowers us to perceive the reality around us which is dominated by complex systems. The importance of this study relies on how complexity theory brings the reader closer to examining the short story genre in a different perspective. It is undeniable fact that short story has always taken a secondary position compared to the genre of novel. However, it is interesting to examine how these narrative theories are well connected to the broader picture of shorter fiction and offers nuggets of completed story lines while opening up possibilities for further expansion.

\section{Methodology}

The approximate structural equivalent of A Snow Garden and Other Stories would be a single hexagonal shaped snowflake (or ice crystal) with six outer projections from its centre. The six pointed structure of the ice crystal is said to render structural 
stability to it. Such a construct binds the water molecules effectively forming a hexagonal pattern (Means, 2019). Joyce's work consists of seven stories, six of them playing out in real time and appearing to converge into/diverge from the 'central' story happening in the past. This effectively mimics the symmetry of an ice crystal. This structural ingeniousness of Joyce's work foregrounds its identity as a short story cycle (Mann, 1989). The stories in A Snow Garden also achieve greater depth when read in connection with each other. They can also be seen as Rachel Joyce's attempt to articulate the complexity of life. They seem to be concerned with studying and visualizing the complex patterns of human lives in a similar vein to the scientific philosophy of Complexity theory. Complexity theory studies the behaviour of complex systems, including human societies, which exhibit traits of interconnectedness (Sardar \& Abrams, 1999, p. 84).

\section{The short story cycle}

The short story cycle is a middle-way genre, and its reputation may be accounted for in its suitability for brevity and the human need for continuity in view of better understanding. Coherence in these stories can be achieved weakly by means of a frame narrative, a similar theme, a distinctive style, or a compositional device (such as structuring the whole on a musical or painterly subject), or achieved strongly by means of shared setting (Dubliners), focus on one character (Alice Munro's Who Do You Think You Are?), or recurrent characters and narrators (Kate Atkinson's Not the End of the World). These works represent short story cycles, while recognizing that a number of other descriptors--series, sequence, novel in stories, composite, etc.--continue to compete for acceptance in critical-theoretical discussions of this comparatively new fictional form. What the short story cycle offers to the reader is a narrative ploy which situates itself between the short story collection and the novel.

The common factor which unites works like James Joyce's Dubliners (1914), Sherwood Anderson's Winesburg, Ohio (1919), Alice Munroe's The Beggar Maid (1978), Edward P. Jones' Lost in the City (1992), Elizabeth Strout's Olive Kitteridge (2008), and Jennifer Egan's A Visit From the Goon Squad (2010) is the utilization of the individual and collective narration techniques of a sequence of stories (Sapadin, 2016). These works appear as short story collections while offering more to the reading experience by linking them together to form cycles, or sequences of stories. A short story cycle, according to Gerald Lynch, consists of standalone stories which "gather accretively to form more meaningful communities of fictions that, in turn, enlarge the meaning of each individual story" (2016, p. 513). Compared to the lengthy, gradual unraveling of a novel or the economic template of a short story, the hybrid form of the short story cycle offers the perfect balance of closure and open-endedness (Kennedy, 1995). It has been called as a mode of writing compatible for the current hyperlink generation which engages with multitasking and suffers from reduced attention spans (Walker, 2019). The links between stories differentiates a short story cycle from a short story collection. 
The connections generate a semblance of narrative coherence. These are generated using several techniques.

Patterns of interconnections in a short story cycle can be achieved using three common techniques. One, by unifying the stories under a shared location or setting; two, by focusing on a single character throughout different stories; and three, by employing a set of recurring characters throughout the stories (Lynch, 2016, p. 513). The short story cycle also makes use of common theme or narrative style to produce the same effect. A cycle, or sequence, of short narrative tales can be achieved through all this while offering possibilities for a larger narrative tale in its cumulativeness. The formalistic tendencies of the short story cycle can be traced back to the period of literary Modernism. According to Paul March-Russell, the short story cycle developed out of experimentations by modernist writers to "capture the many points of view that constitute an objective reality without either dissolving the text altogether or subsuming these multiple perspectives within the homogenising tendency of the realist novel" (2009, p. 103). Gerald Lynch contests that "roots of the short story cycle family can be found in classical epic and European Renaissance narratives that were woven from stories that had been going around since people first told tales to make mysterious life tolerable and themselves collectively a coherent community in time" (2016, p. 527). This also foregrounds the influence of the oral tradition over the short story cycle. Lynch also traces the roots of the short story cycle to eighteenth century epistolary and picaresque novels in English (2016, p. 527). With its rich tradition, the short story cycle offers writers a mode to engage with multiple perspectives of human reality while preserving both the subjective and objective reality of our lives. This also helps to sustain a unique balance between the part and the whole which is necessary to generate narrative tension in a fictional work (Lynch, 2016, p. 518). These features differentiate a short story cycle from any other form of narration.

The short story cycle "relies on layering. An incident takes a significance in the light of the incidents that surround it" (Tansley, 2011, p. 38). The short story cycle's layers can be equated to a palimpsest where written narratives converge upon one another to progressively reveal more. This foregrounds the role of both the writing and construction process of the short story cycle, and the reading process. The short story cycle prioritizes the role of the reader in disentangling and reassembling the layers of connections permeating the stories. In the short story cycle, the reader should construct "a network of associations that binds the stories together and lends them cumulative thematic impact" (Lohafer \& Clary, 1989, p. 149). Different readers may unearth different layers of connections while rereadings by individual readers will also provide further enlightenment. The fundamental feature of a short story cycle is thus the creative output generated by "the tension between the one and the many" (Ingram, 1971, p. 19). The role of the reader in the effectiveness of the short story cycle is also acknowledged by Robert M. Luscher who says that, "the discovery of larger unifying strategies that transcend the apparent gaps between stories" by the readers is a feature of the short story cycle (1989, p. 150). The narrative tension and ploys also rely heavily on the way a writer constructs the short story cycle. According to Forrest Ingram, there are three 
categories of the short story cycle based on the approach of the writer. The first category is the 'Composed' cycles which right from the first story was flawlessly envisioned as a unified whole by the writer. The second is the 'Arranged' cycle which the writer, or editor, arranged after the completion of all the stories in order to produce a semblance of internal connections. The final category is the 'Completed' cycle which the author never 'composed' or 'arranged', but which came into existence when the author recognized the coincidental links between the stories (Lynch, 2016, p. 519).

According to Gerald Lynch the first and last stories of a short story cycle are vital in maintaining the structural ploy of the cycle (2016, p. 524). They establish recurring patterns of place, themes, or characters. While the opening story lays down the caveats necessary to maneuver the reader through the narrative tropes of the cycle, the level of ingeniousness of the concluding story will decide the effectiveness of the whole venture. Gerald Lynch says that "concluding stories of cycles present the most serious challenges to readers and critics, as they bring to fulfillment the preceding recurrent patterns, sometimes re-introducing many of the earlier stories' major characters and images, and restating the cycle's main thematic interests" $(2016$, p. 525). The concluding story is vital for the whole reading process because it can be used to remind the reader about random, peripheral events, or characters in earlier stories. This recapping can produce the penultimate epiphany of connections in the readers, without which the whole ploy of the cycle would disintegrate. Yet, short story cycles need not be closed narratives with all questions resolved; they can be more effective as open ended and cyclical (Smith, 2018, p. 131). The features of a short story cycle have evolved in tune with cultural, artistic, political, and aesthetic changes. Yet, an examining of short story cycles from James Joyce's Dubliners in the early twentieth century to Jennifer Egan's A Visit From the Goon Squad in the twenty-first century reveals similar structural and formal aspects. These today may point towards the hyperlinked lives led by human beings or to our reduced attention spans. Yet the short story cycle has become "a favoured form of both fiction writers and readers who are increasingly engaged in the space between the novel and the short story miscellany" (Lynch, 2016, 528). It is thus a form which operates in a luminal space to portray the interconnections and patterns of human behaviour effectively. By maintaining connections between its stories to engage with the lives of characters even while narrating short standalone tales, Rachel Joyce's A Snow Garden and Other Stories also exhibits narrative techniques of the short story cycle.

There are a number of short story collections that appeared recently. Dear Life (2012) stories display Munro's mysterious ability to take a lifetime or even generations of a single family. These stories and characters are not flashy, but there is little in the way of high concept. This collection includes a few semiautobiographical sketches typically autobiographical in feeling, and, sometimes, entirely built on facts. It is not possible to fully account for the stories and novels that went unpublished and untaught in a literary culture but at least in Lucia Berlin's posthumous collection A Manual for Cleaning Women (2015) and its frank 
rendering of women's lives have a small correction to the record. Ken Liu's The Paper Menagerie and Other Stories (2016) is a collection in which metaphors are fully unwound into tangible results. It gathers some of Liu's most celebrated stories, summaries of which do little to convey the scope of his imagination. Called herself a pessimist, Lesley Nneka Arimah, unfolds her collection of short stories, What It Means When A Man Falls From The Sky (2017) most of which are set in Nigeria and utilize dystopian themes to reveal the bleak consequences of humankind's ruthlessness towards the natural world as well as fellow humans. It narrates the story of a world ravaged by climate change, where a group of scientists try to experiment with a formula to undo what has been done and make it, so the human body can defy gravity.

\section{A Snow Garden as a short story cycle}

Joyce's work presents itself as a short story collection; this is evident in its title $-A$ Snow Garden and Other Stories. Yet while reading the stories one after the other, recurring patterns can be discerned. These include characters, objects, themes, and place. All the stories are set in an unspecified urban locale which the characters' traverse throughout the work. While the setting remains unnamed, the recurrence of specific places underlines the unity (Marais, 2005). In the first story "A Faraway Smell of Lemon", the protagonist Binny finds herself inside a shop selling cleaning products. She observes, "It's been here forever, this shop, but she's never bothered to come inside, just as she's never bothered with the boutique next door that sells party frocks and wedding dresses" (2015, p. 19). In the last story "Trees" Oliver is driving his father home after planting trees. He observes, "outside a ladies' boutique ... three people stood with their backs to the street and gazed at the window display of wedding dresses and party frocks" $(2015$, p. 221$)$. The reader who has been keen to trace the connections from all the stories will also realize that the three people being observed by Oliver are Alan, Alice, and Will from the second story "The Marriage Manual". A unity of place is sustained by Joyce throughout the work; this upholds one condition specified for a work to be classified under the title of a short story cycle.

More than the connections of place, A Snow Garden utilizes the connections forged by the characters throughout the narrative. Binny, the middle-aged mother of the first story expresses her longing for a friend she had when she was young and with whom she has lost touch with. This friend's memories are associated by Binny with the scent of rose-oil perfume she used to wear. It is later revealed abruptly while the second story progresses that this friend is none other than Alice: "Fleetingly Alice pictured the young woman she had once been, who reeked of rose oil and was going to travel the world with a rucksack. She remembered Binny, the girl she had followed everywhere" (2015, pp. 70-71). In the second story "The Marriage Manual" Alice recalls the meeting she had with her son Will's teacher: "Only a few weeks ago she'd had a meeting with his head of year, Miss King, a cherry-faced woman, possibly because she was zipped to the chin in a brand-new puffy skiing jacket" $(2015$, p. 61$)$. This is a reference, similar to Binny's rose-oil reference, which might seem trivial but attains greater meaning when read 
alongside the other stories. The reference achieves further clarity in the third story "Christmas Day at the Airport" where we meet Mrs. King and her unmarried, middle-aged daughters Tracey and Christina. Tracey, "has bought herself an entire new snow outfit and is overheating by the second" (96). The connection with Alice remains unclear till we understand that she is a teacher and Will is her student. These are one among numerous examples where characters who are mere suggestions appear in flesh and blood later on and affirm the sense of interconnection maintained throughout Joyce's work. The characters of Binny, Oliver, Alice, Will, and others recur throughout the narrative and produce the effect of lives unfolding even beyond the boundaries of their stories. A Snow Garden, thus, affirms the condition of repeated characters which makes it a short story cycle.

According to Laura Tansley, in a short story cycle, "Continuing characters or locations as well as themes and patterns create a more tangible link than just themes and patterns, and so would suggest that the piece is to be read as a whole as well as for its composite parts" $(2011$, p. 38). What Tansley is proposing is that the short story cycle creates an elaborate mosaic like structure which can be enjoyed in parts as well as in whole. The enjoyment of a short story cycle will also depend upon the unity of theme, and patterns formed using objects. A Snow Garden uses the theme of the Christmas holiday season throughout its narrative. Linked to the theme are all the objects associated with the season. Yet a specific image generated through various objects recurs throughout the narrative providing it unity. This is the image of the girl in a red coat. This image binds all the characters together in their disparate, yet humane emotions. In the first story Binny observes: "A giant billboard shows an image of a pretty young woman in a 1960s-style red coat looking up at snow" (2015, p. 15). In the second story Alan observes in a Christmas card "a photographic image of a romantic snow scene. It was the young woman in the red coat again" (2015, p. 48). In the third story Magda observes: "From a giant screen, the same short film keeps playing on a loop, something to do with a young woman walking through snow ... the young woman in her red coat" (2015, pp. 82-83). In the fifth story Henry buys a framed picture with the woman in red coat. He also meets a woman in a red coat at the snow garden installation. The penultimate story has Sylvia observing the image of the girl in red coat on a magazine cover with her celebrity son. In the final story Oliver observes the trending advertisements for the holiday season being taken down including, "The girl in the red coat - the girl who had been displayed everywhere . . had embodied the spirit of Christmas" (2015, p. 219-220). Oliver's observation echoes the philosophy of Rachel Joyce in that the image of the girl in red coat represents the connecting theme of the work: the holiday spirit of compassion and forgiveness. This assessment attains further credibility with the central, fourth story happening in 1962 with the protagonist Maureen, a girl in a red coat walking through the snow to attend a Christmas party. This story operates as a centre holding together the other six stories and giving the entire work a unique pattern and identity of a short story cycle.

According to Laura Tansley, the short story cycle engages with the whole process of writing or constructing a narrative (2011, p. 41). Rachel Joyce has 
commented upon the writing process and the interconnected nature of her stories: "It happened by accident. As I wrote the stories, I began to see they were more interesting to me if they existed both separately and as part of one another" (2015, p. 236). Examining A Snow Garden from the perspective of Joyce it can be argued that the work represents the 'Completed' cycle rather than the 'Composed' or 'Arranged' cycles as proposed by Forrest Ingram. The process of writing a short story cycle, may it be 'composed', 'arranged', or 'completed', involves a selfawareness of form which cannot be found in an ordinary short story collection. If not more, the short story cycle is reflecting the fragmentary nature of memory and human lives while engaging with the playful nature characteristic of twenty-first century narratives (Tansley, 2011, p. 44). A Snow Garden, as a work of twenty-first century fiction effectively portrays this fragmentary nature of human lives. Joyce's work is playful in nature as it engages the reader with an elaborate hunt for connections and recurrences educating them about the ways in which human lives in reality are indisputably connected and complex. Joyce's work can be called a short story cycle considering the conditions it fulfils for the title. But even while utilizing the narrative techniques of the short story cycle, A Snow Garden is concerned with portraying the complexity of human lives. Its core arguments on interconnected lives can be better understood with a survey on the principles of Complexity theory.

\section{Complexity theory}

Complexity theory is a scientific and cultural theory associated with the study of complex systems (Hansen, 2017, p. 7). It has been utilized for different purposes in numerous disciplines including, meteorology, thermodynamics, cell biology, anthropology, and learning process (Park, 2017). On a basic level it can be argued that complexity theory engages with the study of complex systems. A complex system is composed of individual components which interact with each other in a dynamic way. The patterns of interactions are hard to predict but achieve a sense of unity in complexity which differentiates it from the behavior of other systems. According to Claire Hansen, "Complex systems are self-organising, dynamic, evolving networks that operate without any centralized control" (2017, p. 8). Ziauddin Sardar and Iwona Abrams categorize the disparate phenomena like the flight patterns of birds, and the process of buying and selling in an economy as complex processes because they seemingly exhibit a lack of order or planning, yet produce patterns in their whole (1999, p. 83). Complexity theory studies the behavior of complex systems to unearth patterns which can help understand the working of the system better. It can be applied to the study of human societies where random, individual human interactions eventually produce the macroscopic construct of the society. Complexity theory also points at the capacity of systems to self-organize without a centralized control. This opens up the possibility of the system achieving greater stability or, conversely, disintegrating into chaos. This is evident on observing civilizations of humanity which flourished and crumbled through the ages. 
There are several features of a complex system pointed out by Ziauddin Sardar and Iwona Abrams. Firstly, complex systems exhibit the characteristic of adaptability. They imbibe changes happening around them and evolve themselves accordingly. Secondly, they foreground the inter-relatedness of things. It focuses upon the way all things are connected and influence each other. Complex systems foreground the ways in which human beings are connected to nature and the social structures which have been created by them. The connections are organic and symbiotic. They rely on feedback, both positive and negative, to sustain them. This is also evident in the case of human relationships inside a society $(1999$, p. 84$)$. Claire Hansen lays down thirteen characteristics of a complex system which can be utilized in analyzing literary texts. One, a complex system consists of numerous parts which can be living or non-living and operate in a decentralized way. Two, the parts must exhibit dynamic interaction between each other and influence each other. Three, the interactions between the parts are nonlinear and random. Four, there must be positive and negative feedback to sustain the system. Five, the complex system is open to interact with external factors; it is not a closed entity. Six, it sustains itself based on instability and disorder. Seven, they operate using memories of their past behavior. Eight, individual elements operate with near to no knowledge of the working of the system as a whole. Nine, there are multiple layers of interaction in a complex system. Ten, it exhibits self-similarity across different levels. Eleven, it exhibits self-organization. Twelve, it exhibits 'emergence' or the creation of new patterns through self-organization; and lastly, the behavior of a complex system is determined by an 'attractor' or the system's preferred behavioral state into which it attempts to return over time (2017, pp. 9-11).

By employing complexity theory in the study of literature one can discern the ways in which human consciousness and identity work (Sim, 2002, p. 94). The flexibility of the theory enables its assimilation into numerous disciplines (Livingston, 2011, pp. 43-44). Fictional works which represent the interconnected nature of human existence can be studied using complexity theory. An examination of Rachel Joyce's A Snow Garden and Other Stories can also be effectively made using the principles of complexity theory. Since it has already been established in the paper that Joyce's work is a short story cycle which foregrounds interconnections, the thirteen principles of a complex system can be applied to the work to argue how Joyce appropriates the principles of complexity to narrate the interconnected nature of human lives. It also amplifies how complexity theory offers an edge to the power of the short story that the larger fiction does not usually employ.

\section{Complexity of life in A Snow Garden}

All the stories in Joyce's work deal with human relationships in a state of flux. The complexity of human behavior as something which is affected by external circumstances is also highlighted throughout the stories. Factors which determine the course of life of the characters remain unpredictable; this points at the vital role of causality in A Snow Garden. Joyce's attempt to use the urban setting as a 
backdrop adds another layer of complexity to the lives being narrated. Paul MarchRussell argues that the short story cycle "has been an effective tool in describing the modern city where social ties are looser, kinship systems less structured and personal identities more alienated" (2009, p. 109). A Snow Garden upholds these traits while portraying urban lives adding to its complexity. The compatibility of Joyce's work as one engaging with human lives as complex systems can be tested using the thirteen characteristics of the complex system as proposed by Claire Hansen.

The first condition for a complex system requires the presence of numerous parts, both living and non-living, which operate in a decentralized way. In A Snow Garden, the parts which form the complex system are the characters and objects which appear throughout the narrative. The image of the girl in red coat appears as different objects and inspires the lives of characters in a random manner throughout the work. Showcasing the qualities of a short story cycle, Joyce's work has individual standalone stories where characters follow their arc to a conclusion. But observing the work as a whole shows how Joyce ingeniously links the fates of peripheral characters and objects in one story with the major characters in another. The resolutions achieved by characters are in this sense 'decentralized'. The role of causality and randomness is, thus, uplifted throughout A Snow Garden. In Binny's story we find her life falling apart when her boyfriend Oliver leaves her for another woman, Sally. Towards the end of the story Binny, who had decided to immerse herself in grief and self-pity during Christmas, finds comfort from a stranger, a shop assistant, who teaches her to face rejection and loss. The story is resolved when Binny decides to pick up the pieces of her life and reclaim the Christmas spirit. But the individual parts of it, including the characters Binny and specific objects, including the girl in red coat indirectly, affect the resolution of the next tale.

In the second tale, Binny's presence is reduced to a Christmas card with the image of the girl in red coat that she sends to Alice, the protagonist of the second tale. The contact is random and a result of Binny's transformation at the end of the first story where she decides to reclaim her lost contacts at Christmas. This attains significance later on when Alice and Alan start to bicker among themselves and to confess upon their dissatisfaction hidden in a seemingly stable marriage. This leads to Alice recollecting her old friendship with Binny. While the second story ends with Alan and Alice reconciling with each other, the implication of the episode will attain full significance later on in the last story. The last story focuses upon the plight of Oliver, Binny's boyfriend from the first tale. Yet, exhibiting the level of decentralization evident in a short story cycle, the last story enlarges upon the narrative arcs of Binny and Alice. When Oliver arrives at Binny's place to borrow her van he observes: "There was a smell in the house he hadn't noticed before, so full it was like another person. 'Rose oil,' said Binny, as if reading his thoughts. 'An old friend of mine came over for coffee" (2015, p. 204). The last story doesn't even specify Alice's name but the discerning reader can ascertain this easily. The narrative arcs of Binny and Alice with all their supporting characters and objects confirm the decentralized nature of the individual components being narrated. 
The second condition for a complex system requires the individual parts to interact in a dynamic way. As Hansen would say, "The interaction is usually localized, and may comprise communication between individuals, groups and the environment" (2017, p. 9). The third condition which requires a complex system to interact in a nonlinear way can be connected with this. Both these conditions can be seen narrated throughout Joyce's work. But for the sake of brevity focus will be on the episode of Coco and the goat. In the first story Binny's little daughter Coco wants a goat as a gift for Christmas. This is casually commented upon as the story concludes. In the third tale "Christmas Day at the Airport" the animal reception centre at the airport is overwhelmed by the presence of illegal animals at the airport including a donkey, four cheetahs, a terrapin, and a goat. The assistant at the centre decides to reach out to people who might adopt the animals at the airport with the help of the local radio station by relaying this message to its listeners. Later she tells her manager that a little girl has rung the radio station showing interest to adopt the goat. She says, "The little girl says she wants to adopt it. But not the terrapin. Her mother has a van" (Joyce, 2015, p. 104). These are random, seemingly trivial suggestions which achieve full meaning only in the last story where Binny says that Coco got her goat for Christmas. This is one among numerous examples where $A$ Snow Garden showcases individual elements, both human and non-human, interacting in dynamic and nonlinear ways.

The fourth and fifth conditions of a complex system can be combined to examine A Snow Garden. According to them a complex system is open ended and is sustained by positive (turbulent) and negative (stabilizing) feedback. The open ended nature of a complex system automatically generates feedback through its interactions with its environment. In Joyce's work characters interact with each other and their surroundings in an open ended way. Their interactions generate feedback which would later determine the course of the whole narrative. Henry's story exhibits this trait perfectly. Henry, a divorced man owing to mental health issues, has to engage his two sons Conor and Oliver for a few days during Christmas season. He is hesitant and wary that he might ruin his weakening ties with his sons. $\mathrm{He}$, thus, behaves cautiously and in a 'closed' manner initially. He had promised them snow for Christmas but the weather conditions promise none for the season. On a lonely trip to the park Henry spies a solitary garden covered with snow. He equates this as a hallucination and thinks that he is losing his mental stability again. This event which might have generated positive feedback in his life, ruining the prospects of further ties with his sons, transforms into negative feedback. Henry embraces the open ended nature of life by risking his sanity and taking his sons to the snow garden. This produces negative feedback (stability) when it is revealed that the snow garden is a prop for a photo shoot. His sons enjoy their time at the artificial snow garden; their trust in their father is consolidated. The open ended nature of life as displayed through the example of Henry shows how chance interactions with the external environment can propel complex lives into stability.

A Snow Garden also upholds the sixth condition by portraying how human lives as complex systems are sustained using instability and disorder. This is 
evident throughout the work. Binny's life which is highly disorganized results in her losing her boyfriend Oliver. The arguments on marriage raised by Alan and Alice help revitalize their relationship. The disorder at the airport ends in Magda giving birth to her child in an episode which beautifully mimics the nativity of Christ. Maureen's choice to defy her parents and the comfort of a stable life to go to the midnight Christmas party changes the fortunes of her life. The elements of instability and disorder are also seen in the stories of Henry and Oliver. The seventh characteristic of a complex system is that it operates based on its past behavior. This can be seen in the portrayal of deep and ancient connections of social rituals, especially those associated with Christmas, which repeat periodically throughout the narrative of $A$ Snow Garden. The memories of past behaviors affect those in the present. When Magda is giving birth to her child at the airport she finds consolation from the image of the girl in red coat. Time entangles and the echoes of the original nativity of Christ combined with its later representations in the festivities of Christmas amalgamate into the fate of Magda. Observing the image of the girl in red "Magda hears the calls from the friends the girl has left behind, she sees torches, she smells the flinty coldness of snow" (Joyce, 2015, pp. 109-110). The association with the past is clarified in the next story set in the past where we find Maureen, a girl in red coat, traveling through snow with her friends who are carrying torches to celebrate Christmas.

A Snow Garden also exhibits the eighth characteristic of the complex system. It portrays lives which seem to unravel without much interaction with each other. Character arcs are self-contained inside a story. But the connections they establish remain vague until the entire work is completed. The snow garden which Henry visits is revealed to be a prop for a photo shoot which was later abandoned. The significance of it is only achieved in the next story where we find that it was set for the celebrity singer ' $X$ ', the protagonist Sylvia's son, who was to do a photo shoot there but backed out at the last moment. The ninth characteristic of a complex system exhibiting multiple layers of interaction can also be seen in A Snow Garden. Interaction happens among characters and objects throughout the work. The tenth characteristic of self-similarity is achieved in Joyce's work using the repeated image of the girl in red. There is also the repeated reference to the basic colors of objects including blue, green, yellow, and red. In the story "The Marriage Manual", Alice finds a letter written by Will to Santa which says he wants a dress, "A green one. With a sweetheart neckline and a ribbon belt" (Joyce, 2015, p. 73). Alan, Will's father, has fitted a green porch light. Mrs. King and her daughters are stuck at the airport while they are about to go on a trip to see the northern lights. The assistant at the animal reception centre has dyed her hair green. This pattern is also repeated with the other colors creating self-similarity across scales. This is also the case of objects, primarily the girl in red coat superimposed on numerous objects.

The eleventh and twelfth features of a complex system: that it exhibits selforganization and emergence can also be seen in A Snow Garden. All the individual stories of the work feature individual lives which are at a crossroads. Characters from Binny to Oliver have decisions to make and this propels the narrative towards uncertainty. But at the end of the whole work when connections have been traced 
between individual lives it can be ascertained that the complex human society depicted has achieved self-organization. Patterns of human behavior emerge out of the individual stories. Joyce asserts this philosophy of self-organization and emergence at the end of the last story. She says: "A Story only made complete sense when it was over, when you could look back and say, this happened and then that happened and so this is where it ended" (2015, p. 223). The thirteenth characteristic of a complex system is that it has an 'attractor' or a preferred behavioral state into which it returns periodically. In A Snow Garden, the attractor which the characters return to is that of compassion. Binny decides to forgive Oliver and accept him back. Oliver decides to show kindness towards his estranged father. Alice and Alan forgive each other's shortcomings. They show compassion towards their son Will by fulfilling his desire to dress up like a girl. Magda eventually receives compassion from the motley of people at the airport. Maureen shows compassion towards a lonely young man at the Christmas party by accepting his proposal for marriage. $\mathrm{X}$ gets warmth and compassion he sorely needs from his mother Sylvia. Throughout the work it can be observed that characters interact in complex ways showcasing a plethora of human emotions and behaviors yet they ultimately return to the 'attractor' of compassion.

\section{Conclusion}

Rachel Joyce's A Snow Garden and Other Stories merits the title of a short story cycle. It connects the individual stories, which are standalone, with each other creating a larger canvas than an ordinary short story collection. Unity of place is utilized in the narrative which deals with urban identity. It also connects the stories using recurring characters, themes, and objects which create an elaborate mosaic beautifully realized as a whole and in parts. The ingenuity of the narrative also resides in its portrayal of the complexity of human lives using the form of the short story cycle. The principles of the complex system as propounded by complexity theory are put into practice in the narrative. Interconnected stories function as a medium to explore the interconnected lives humans lead in the contemporary times. It also points at the medium of the short story cycle as an evolving form which is appropriated by many contemporary writers to represent human lives (D'hoker, 2013). While asserting the patterns of behavior exhibited by humans in societies, Joyce's work also engages with the need to recognize the role of each individual in the collective human society. It asserts the role played by repetition, randomness and chance in human interactions. Ultimately, Rachel Joyce's A Snow Garden becomes a brilliant portrayal of the unpredictability of interconnected human lives in society.

Acknowledgement: The Author would like to thank the Arab Open University for supporting this research paper. 
Shaju Nalkara Ouseph

Arab Open University, KSA

ORCID Number: 0000-0003-2048-4260

Email: snalkara@arabou.edu.sa

\section{References}

D'hoker, Elke. (2013). 'The short story cycle: Broadening the perspective'. Short Fiction in Theory and Practice, 3 (2): 151-59.

Hansen, Claire. (2017). Shakespeare and complexity theory. London: Routledge.

Ingram, Forrest L. (1971). Representative short story cycles of the twentieth century. Paris: Mouton.

Joyce, Rachel. (2015). A snow garden and other stories. London: Black Swan.

Kennedy, J., Gerald. (1995). 'Introduction: The American short story sequence Definitions and implications'. In J. Gerald Kennedy (Ed.), Modern American short story sequences, vii-xv. Cambridge: Cambridge UP.

Livingston, Ira. (2011). 'Chaos and complexity theory'. In Bruce Clarke and Manuela Rossini (Eds.), The routledge companion to literature and science, 41-50. New York: Routledge.

Lohafer, Susan and Jo Ellyn Clarey (eds.). (1989). Short story theory at a crossroads. Louisiana: Louisiana State UP.

Luscher, Robert. (1989). 'The short story sequence: An open book'. In Susan Lohafer and Jo Ellyn Clarey (Eds.), Short story theory at a crossroads, 148167. Louisiana: Louisiana State UP.

Lynch, Gerald. (2016). 'Short story cycles: Between the novel and the story collection'. In Dominic Head (Ed.), The cambridge history of the English short story, 513-529. Cambridge: Cambridge UP. 
Mann, Susan G. (1989). The short story cycle: A genre companion and reference guide. Westport: Greenwood.

Marais, Sue. (2005). "'Queer small town people": Fixations and fictions of fellowship in the modern short story cycle'. Current Writing: Text and Reception in Southern Africa, 17 (1): 14-36.

March-Russell, Paul. (2009). The short story: An introduction. Edinburgh: Edinburgh UP.

Means, Tiffany. (2019). 'The science of snowflakes explained'. Thought Co. https://www.thoughtco.com/science-of-snowflakes (Retrieved on 6 October, 2020)

Park, Jun. (2017). 'An introduction to complexity theory'. Medium. https://medium.com/@junp01/an-introduction-to-complexity-theory (Retrieved on 6 October, 2020).

Sapadin, Benjamin. (2016). Celebrating short story cycles. New York Public Library. $\quad$ https://www.nypl.org/blog/2016/05/03/short-story-cycles (Retrieved on 6 October, 2020).

Sardar, Ziauddin and Iwona Abrams. (1999). Introducing chaos. Cambridge: Icon Books.

Sethi, Anita. (2016). 'A snow garden and other stories review - pictures of lives, broken and whole'. The Guardian. https://www.theguardian.com/books/2016/dec/18/a-snow-garden-and-otherstories-review-pictures-of-lives-rachel-joyce (Retrieved on 6 October, 2020).

Sim, Stuart. (2002). 'Chaos theory, complexity theory and criticism'. In Julian Wolfreys (Ed.), Introducing Criticism at the 21st Century, 89-105. Edinburgh: Edinburgh UP.

Smith, Jennifer J. (2018). The American short story cycle. Edinburgh: Edinburgh UP.

Tansley, Laura. (2011). 'The frame within a frame: a short-short story sequence theory in a sequence of short-shorts'. Short Fiction in Theory and Practice, 1 (1): $37-45$. 
Walker, Amelia. (2019). 'Stories for hyperlinked times: The short story cycle and Rebekah Clarkson's Barking Dogs'. The Conversation. https://theconversation.com/stories-for-hyperlinked-times-the-short-storycycle-and-rebekah-clarksons-barking-dogs (Retrieved on 6 October, 2020).

Werlock, Abby. (Ed.). (2010). The facts on file companion to the American short story. New York: Facts on File. 